\title{
Masked comparison of two silicone hydrogel bandage contact lenses after photorefractive keratectomy
}

Homa Bagherian, $\mathrm{MD}^{1}$; Hamed Momeni-Moghaddam, $\mathrm{PhD}^{2,3}$; Siamak Zarei-Ghanavati, $\mathrm{MD}^{1}$; James S. W. Wolffsohn, $\mathrm{PhD}^{4}$; Shehzad A. Naroo, $\mathrm{PhD}^{4}$

1. Eye Research Center, Mashhad University of Medical Sciences, Mashhad, Iran.

2. Health Promotion Research Center, Zahedan University of Medical Sciences, Zahedan, Iran.

3. Department of Optometry, School of Paramedical Sciences, Mashhad University of Medical Sciences, Mashhad, Iran.

4. School of Life and Health Sciences, Aston University, Birmingham, UK.

Funding/Support: This research did not receive any specific grant from funding agencies in the public, commercial, or not-for-profit sectors.

Financial Disclosures: The authors declare that they have no conflict of interest.

Corresponding author: Hamed Momeni-Moghaddam, $\mathrm{PhD}$;

E-Mail: hmomeni_opt@yahoo.com

Tel: +989155337952

Address for reprints: H. Momeni-Moghaddam, Sedaghat Eye Clinic, Molla-Sadra 2 Str., Ahmadabad Blvd., Mashhad, Iran. 


\section{ABSTRACT}

Purpose: To compare the efficiency and safety of two bandage contact lenses after photorefractive keratectomy (PRK).

Methods: In this double-blind study, 45 patients (90 eyes) received PRK in both eyes and wore bandage contact lenses (BCLs), PureVision (Bausch \& Lomb, Rochester, NY, USA) in one eye and PureVision2 (Bausch \& Lomb, Rochester, NY, USA) in the other eye, randomly assigned. The medication regimen after surgery was the same for both eyes. The epithelial defect's size, conjunctival hyperemia and lens centration were graded objectively using slit-lamp biomicroscopy on days 1,3 and 5 after surgery. Also ocular symptoms of discomfort including tearing, photophobia, foreign body sensation and visual fluctuations were assessed subjectively at each visit.

Results: The mean epithelial defect size on the first day after operation was similar in eyes fitted with PureVision $\left(30.08 \pm 5.30 \mathrm{~mm}^{2}\right)$ and PureVision2 $\left(30.25 \pm 5.72 \mathrm{~mm}^{2}\right)$ lenses. $(\mathrm{p}=0.79)$ Contact lens deposits and bulbar hyperaemia on days 1 and 3 after PRK were similar between the two eyes, but were significantly greater on day 5 for PureVision2 lenses. $(p=0.02 ; p=0.04$ respectively) There was no difference in contact lens decentration, and discomfort symptoms including pain, tearing, foreign body sensation, photophobia and visual fluctuations between the eyes fitted with PureVision and PureVision2. ( $>0.05)$

Conclusions: PureVision and PureVision2 contact lenses are equivalent as bandage lenses in the important aspects corneal re-epithelialization and subjective comfort., although PureVision2 led to a higher incidence of contact lens deposits and conjunctival hyperemia early post-PRK. 
Key Words: Silicone hydrogel; Bandage contact lens; Photorefractive keratectomy PRK; Balafilcon A

\section{INTRODUCTION}

Bandage contact lenses (BCLs) are widely used after corneal refractive surgery to reduce pain, promote epithelial healing, provide mechanical and structural protection, maintain corneal hydration and facilitate the visual recovery process.[1,2] The introduction of silicone hydrogel soft contact lenses improved corneal oxygenation and mitigated the complications related to hypoxia; additionally, they have been found to attenuate the patient's discomfort compared to conventional hydrogel lenses mostly due to faster re-epithelialization after refractive surgery.[3, 4] There are a wide variety of silicone hydrogels commercially available.[5] The key features considered to select the optimum BCL include its oxygen permeability, water content, wetting agents, diameter, base curve and modulus.[6]

Several studies have investigated the effect of different materials on the epithelial healing, visual outcomes and subjective assessment of pain and discomfort after corneal refractive surgery; [7-11] however, they could not determine which specific parameters influence the contact lens's performance or its role during the healing process. PureVision and PureVision2 silicone hydrogel $(\mathrm{SiH})$ contact lenses are made of the Balafilcon $\mathrm{A}$ that contains $36 \%$ water and AerGel ${ }^{\mathrm{TM}}$ technology lens material that are manufactured by cast molding process. Surface treatment is performed using the Performa ${ }^{\mathrm{TM}}$ process which transforms hydrophobic silicone to hydrophilic silicate. These two lenses are similar except for center thickness and hence Dk/t. [4, 12, 13] Therefore, this study allows the effect of two BCLs, PureVision and PureVision2, on wound healing, conjunctival hyperemia, subjective symptoms and contact lens deposits following PRK to 
be investigated with minimal effects from other confounding factors such as lens design and other material properties.

\section{PATIENTS AND METHODS}

In this prospective double-masked, contralateral, comparative clinical study, participants were 45 myopic patients (90 eyes) undergoing bilateral PRK who met the inclusion criteria. Of these patients, $37(82 \%)$ were women. The mean age was $29.4 \pm 6.5$ years with a range 19 to 45 years. The aims of this project were clearly clarified to the patients in advance, and an informed consent was signed by all participants. All steps of this study were conducted under the provision of the tenets of the Declaration of Helsinki and the study was approved by the local ethics committee.

The inclusion criteria were myopia less than or equal to 8.00 diopters (D) and astigmatism $\leq 2.00$ D, age at least 18 years old, normal corneal topo/tomography, stability of refraction at least 1 years $< \pm 0.25 \mathrm{D}$ in spherical equivalent $-\mathrm{SE}$ ), spectacle distance corrected visual acuity (SDCVA) at least 20/20, no ocular and systemic diseases and not pregnant or breast feeding.

A complete ophthalmic examination including distance uncorrected visual acuity (DUCVA) and spectacle distance corrected visual acuity (SDCVA), manifest and cycloplegic refraction using cyclopentolate hydrochloride $1 \%$, slit lamp biomicroscopy examination, corneal topography using Placido-disk based topography (Tomey Corp, Nagoya, Japan), corneal tomography using Orbscan (Orbscan IIz, Bausch \& Lomb, Rochester, NY, USA), Hartmann-Shack aberrometry (Zywave aberrometer, Bausch \& Lomb, Rochester, NY, USA) and fundus examination after pupil dilation was conducted for each patient. 


\section{Surgical technique}

All PRK procedures were performed by one surgeon (S.Z) and both eyes of each patient were treated consecutively. Initially, a topical anesthetic (tetracaine $0.5 \%$ ) was applied 3 times. Subsequently, 20\% ethanol through an $8 \mathrm{~mm}$ semi-sharp corneal marker was applied for 20 seconds to soften the corneal epithelium. A weck cell sponge was used to remove the alcohol and the cornea was rinsed with $40 \mathrm{ml}$ of a balanced salt solution (BSS). Corneal epithelium was removed by weck sponge. Stromal ablation was performed using Technolas 217-Z100 excimer laser (Bausch \& Lomb, Rochester, NY, USA), and was followed by application of Mitomycin-C $0.02 \%$ for 5 seconds per each diopter of SE treatment and irrigation using 40cc of BSS. At the end of procedure, one eye of each patient was fitted with PureVision (PureVision ${ }^{\mathrm{TM}}$ Bausch \& Lomb, Rochester, NY, USA) and the other eye with PureVision 2 (PureVision2 ${ }^{\mathrm{TM}}$ Bausch \& Lomb, Rochester, NY, USA) bandage contact lens, assigned randomly. Slit-lamp biomicroscopy evaluation at the end of surgery showed an appropriate fit of BCL in all eyes. The characteristics of these lenses are shown in Table 1.

Table 1: Contact lenses characteristics.

\begin{tabular}{lcc}
\hline \multicolumn{1}{c}{ Variables } & PureVision & PureVision2 \\
\hline Material & Balafilcon A & Balafilcon A \\
Surface treatment & Plasma oxidation & Plasma oxidation \\
Optics technology & Aspheric optics & Aspheric optics \\
Dk (10 $\mathbf{1 1}^{\text {) }}$ & 91 & 91 \\
Central thickness@-3.00 (mm) & 0.09 & 0.07 \\
DK/t $\left(\mathbf{1 0}^{-\boldsymbol{9}}, \mathbf{- 3 . 0 0 D}\right)$ & 101 & 130 \\
Water content $(\%)$ & 36 & 36 \\
\hline
\end{tabular}




\begin{tabular}{lcc}
\hline Diameter (mm) & 14.0 & 14.0 \\
Base curve (mm) & 8.6 & 8.6 \\
Optic zone for -3.00 D (mm) & 8.9 & 9.0 \\
Wetting agent & None & None \\
Modulus (MPa) & 1.1 & 1.1 \\
UV blocking & No & No \\
\hline
\end{tabular}

Dk unit: $\left(\mathrm{cm}^{2} / \mathrm{sec}\right)(\mathrm{mlO} 2 / \mathrm{ml} \mathrm{x} \mathrm{mmHg}) 10^{-11}$

Patients and surgeon were masked to the type of BCL fitted in each eye. The same surgeon evaluated the BCL's fitting using slit lamp biomicroscopy. The mean and standard deviation (SD) of preoperative refractive status, keratometry reading and central corneal thickness in the eyes fitted with the two BCLs which are shown in Table 2 did not show significant difference. (Table 2)

Table 4: Mean and standard deviation (SD) of preoperative variables in the eyes fitted with PureVision and PureVision2. ( $\mathrm{n}=90$ eyes $)$

\begin{tabular}{cccc}
\hline Variables & $\begin{array}{c}\text { PureVision } \\
(\mathbf{n}=\mathbf{4 5} \text { eyes })\end{array}$ & $\begin{array}{c}\text { PureVision2 } \\
(\mathbf{n}=45 \text { eyes })\end{array}$ & p-value \\
\cline { 2 - 3 } & $\begin{array}{c}\text { Mean } \pm \text { SD } \\
\text { (Range) }\end{array}$ & $\begin{array}{c}\text { Mean } \pm \text { SD } \\
\text { (Range) }\end{array}$ & \\
Sphere (D) & $-2.92 \pm-1.46$ & $-2.82 \pm-1.55$ & $\mathbf{0 . 1 7}$ \\
& $(0.00$ to -6.5$)$ & $(0.00$ to -6.5$)$ & \\
Cylinder (D) & $-0.59 \pm-0.69$ & $-0.72 \pm-0.75$ & $\mathbf{0 . 0 7}$ \\
& $(0.00$ to -2.75$)$ & $(0.00$ to -3.00$)$ & \\
Spherical equivalent (D) & $-3.18 \pm-1.42$ & $-3.21 \pm-1.44$ & $\mathbf{0 . 6 8}$ \\
& $(-0.75$ to -6.75$)$ & $(-0.5$ to -6.75$)$ & \\
Mean Keratometry (D) & $44.06 \pm 1.22$ & $44.10 \pm 1.20$ & $\mathbf{0 . 2 0}$ \\
\hline
\end{tabular}




\begin{tabular}{lccc}
\hline & $(41.64$ to 46.36$)$ & $(41.65$ to 46.28$)$ & \\
Corneal thickness $(\boldsymbol{\mu m})$ & $545.6 \pm 37.32$ & $547.64 \pm 38.84$ & $\mathbf{0 . 0 9}$ \\
& $(472$ to 612$)$ & $(478$ to 621$)$ & \\
\hline
\end{tabular}

\section{Medications and Postoperative follow-ups}

The postoperative medication regimen was the same for both eyes and included topical diclofenac sodium $0.1 \%$ (Allergan, Dublin, Ireland) administrated 6 times daily for 2 days, levofloxacin (Oftaquix, Santen Pharmaceutical, Osaka, Japan) drops 5mg/ml 6 times daily until complete corneal re-epithelialization, and betamethasone (Betasonate, Sina Daru, Iran) eye drop used for 1 month, and then replaced with fluorometholone $0.1 \%$ (Allergan Ltd, Dublin, Ireland) eye drop every 6 hours in a tapering schedule for 2 months. Preservative-free artificial tears (Artelac Advanced, Bausch \& Lomb, Rochester, NY< USA) were administrated frequently in the first month until complete re-epithelialization and then gradually tapered with attention to the ocular surface condition.

All patients were followed up at 1,3 and 5 days postoperatively by the same surgeon. Postoperative assessments were digital slit-lamp biomicroscopy (BQ 900, Haag-Streit, Koniz, Switzerland) to evaluate the integrity of corneal epithelium, corneal infiltration, conjunctival hyperemia, lens decenteration and contact lens deposits. 
The epithelial defect size was calculated based on the remaining area (A) of epithelial defects using the following equation:[14]

$\mathrm{A}==\pi[(\mathrm{a}+\mathrm{b}) / 4]^{2}$, where " $\mathrm{a}$ " and " $\mathrm{b}$ " refer to the shortest and longest dimension of epithelial defect, respectively.

For each patient, the BCL was removed when there was no observable epithelial defect and the day of epithelial healing was recorded in each case.

Contact lens deposition was graded based on a five point scale,[8] and lens decenteration and conjunctival hyperemia using a four point scale.[15] (Tables 3 and 4)

Table 3: Contact lens deposit grading scale.

\begin{tabular}{cc}
\hline Grade & Contact lens deposit \\
\hline $\mathbf{0}$ & No deposit \\
$\mathbf{1}$ & Up to $25 \%$ of the lens surface \\
$\mathbf{2}$ & Up to $50 \%$ of the lens surface \\
$\mathbf{3}$ & UP to $75 \%$ of the lens surface \\
$\mathbf{4}$ & Over than $75 \%$ of the lens surface \\
\hline
\end{tabular}


Table 4: Lens decenteration and conjunctival hyperemia grading scale using a modified Corneal and Contact Lens Research Unit (CCRLU) grading scale.

\begin{tabular}{ccc}
\hline Grade & Lens decenteration & Conjunctival hyperemia \\
\hline $\mathbf{0}$ & Centered lens or decentration, less than $1 \mathrm{~mm}$ & Very slight \\
$\mathbf{1}$ & Decentration between $1-2 \mathrm{~mm}$ & Slight \\
$\mathbf{2}$ & Dcenteration between $2-3 \mathrm{~mm}$ & Moderate \\
$\mathbf{3}$ & Decenteration more than $3 \mathrm{~mm}$ & Sever \\
\hline
\end{tabular}

Also, all patients completed a subjective questionnaire grading pain, tearing, foreign body sensation, photophobia and visual fluctuations on a five point score (0-4) on the first, third and fifth days after surgery.[8]

\section{Statistical Analysis}

The data was analyzed in SPSS-21 software using the paired-sample T test or a non-parametric test (Wilcoxon signed rank test) based upon whether the data displayed a normal distribution or not (Kolmogorov-Smirnov test <0.05). A p-value less than 0.05 was considered significant statistically. 


\section{RESULTS}

The mean size of epithelial defect in the eyes fitted with PureVision and PureVision2 on the first day after surgery was $30.08 \pm 5.30 \mathrm{~mm}^{2}$ (range: $20.82-44.16 \mathrm{~mm}^{2}$ ) and $30.25 \pm 5.72 \mathrm{~mm}^{2}$ (range: 6.97 to $45.94 \mathrm{~mm}^{2}$ ), respectively with no statistically significant difference between the two contact lenses. $(\mathrm{p}=0.79)$ The defect size on the third post-operative day was $0.08 \pm 0.29 \mathrm{~mm}^{2}$ (range: $0.0-1.77 \mathrm{~mm}^{2}$ ) with PureVision and $0.14 \pm 0.55 \mathrm{~mm}^{2}$ (range: $0.0-3.14 \mathrm{~mm}^{2}$ ) with PureVision2. $(\mathrm{p}=0.47)$ After five days, re-epithelialization was completed and BCLs were removed from all eyes except in one eye (fitted with PureVision2) that healed seven days after surgery. However, there was no statistically difference in corneal epithelial healing between the two lenses at all visits.

The difference between the mean conjunctival hyperemia between the two lenses was not statistically significant on days $1(\mathrm{p}=0.37)$ and $3(\mathrm{p}=0.53)$; however, conjunctival hyperemia on day 5 was significantly higher in the eyes fitted with PureVision2 than those with PureVision. ( $\mathrm{p}=$ 0.04). (Figure 1)

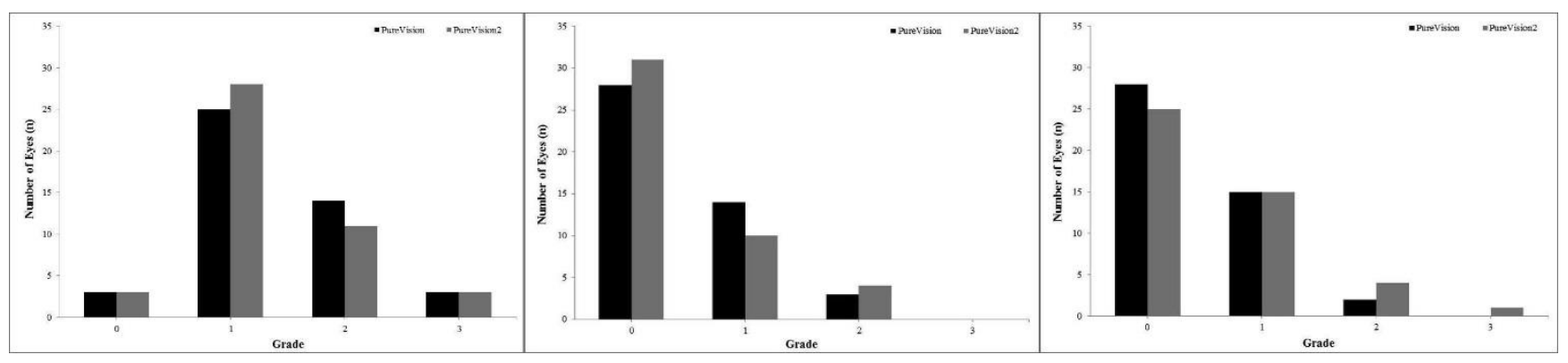

Figure 1: 
More deposits were observed on the surface of PureVision2 compared to PureVision lens 5 days after PRK $(p=0.02)$. However, there was no statistically significant difference in deposits' level on days $1(\mathrm{p}=0.24)$ and $3(\mathrm{p}=0.06)$. (Figure 2$)$

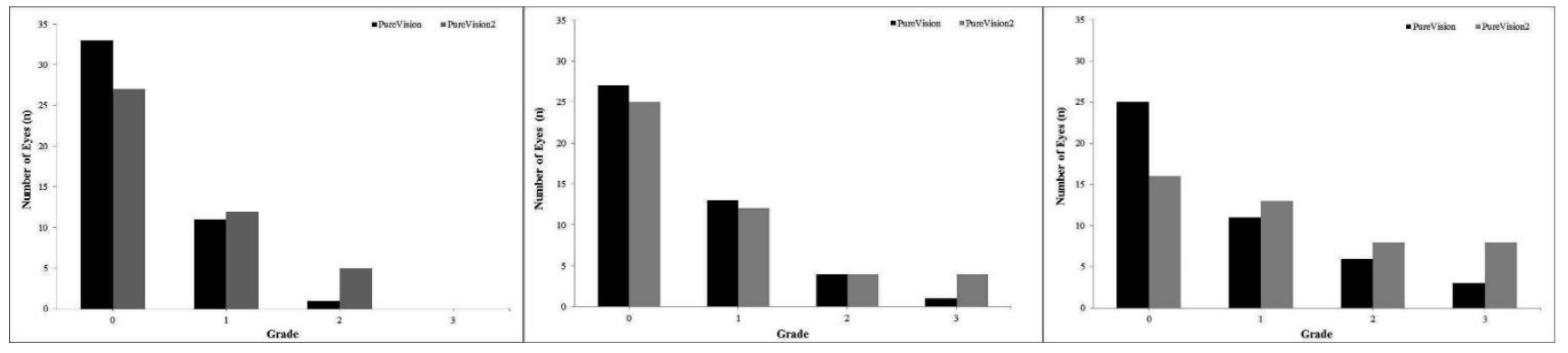

Figure 2:

There was no difference in the mean lens decenteration between the two contact lenses on days $1(\mathrm{p}=0.79), 3(\mathrm{p}=0.42)$ and $5(\mathrm{p}=0.11)$ after surgery. (Figure 3$)$

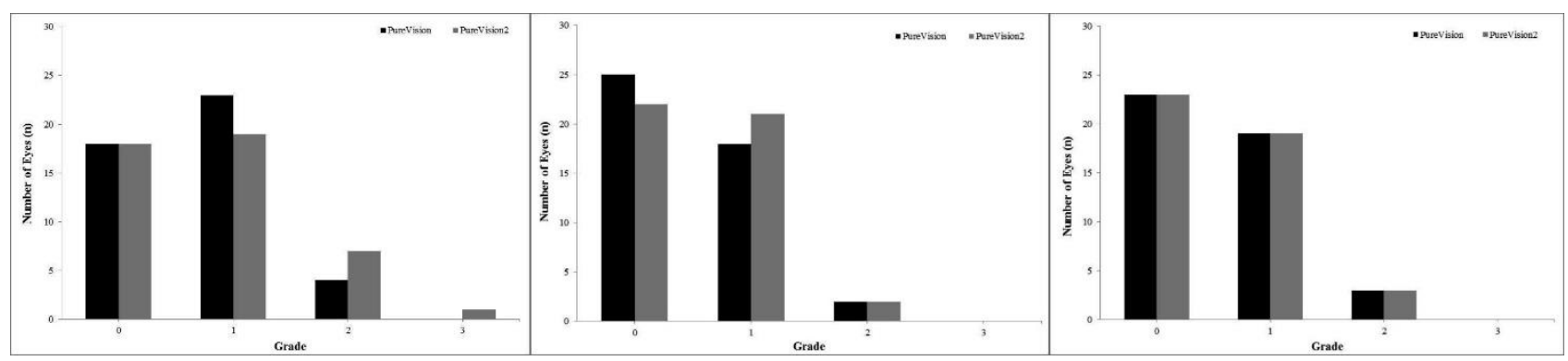

Figure 3:

There were no significant difference on days 1,3 and 5 after the operation in tearing $(p=0.87,0.79$ and 0.39 , respectively), pain ( $\mathrm{p}=0.11,0.53$ and 0.11 , respectively), foreign body sensation $(\mathrm{p}=$ $0.71,0.47$ and 0.51 , respectively), photophobia ( $\mathrm{p}=1.00,1.00$ and 0.32 , respectively) and visual 
fluctuation ( $\mathrm{p}=1.00,0.34$ and 0.71 , respectively) between the eyes fitted with PureVision and those with PureVision2. (Table 5)

Tables 5: Frequency distribution of postoperative ocular discomfort symptoms separately for both BCLs. $(n=90$ eyes $)$

\begin{tabular}{|c|c|c|c|c|c|c|c|c|c|c|c|}
\hline \multirow{3}{*}{\multicolumn{2}{|c|}{ Variables }} & \multicolumn{2}{|c|}{ Pain } & \multicolumn{2}{|c|}{ Tearing } & \multicolumn{2}{|c|}{$\begin{array}{c}\text { Foreign } \\
\text { body } \\
\text { sensation }\end{array}$} & \multicolumn{2}{|c|}{$\begin{array}{c}\text { Photophobi } \\
\text { a }\end{array}$} & \multicolumn{2}{|c|}{$\begin{array}{c}\text { Visual } \\
\text { fluctuation }\end{array}$} \\
\hline & & PV & PV & $\mathbf{P V}$ & PV2 & PV & $\mathbf{P V}$ & $\mathbf{P V}$ & PV2 & PV & PV2 \\
\hline & & & 2 & & & & 2 & & & & \\
\hline \multirow{5}{*}{$\begin{array}{l}\text { First } \\
\text { day }\end{array}$} & $\mathbf{0}$ & 11 & 12 & 5 & 3 & 6 & 12 & 3 & 3 & 13 & 14 \\
\hline & 1 & 13 & 15 & 10 & 12 & 13 & 6 & 10 & 11 & 13 & 11 \\
\hline & 2 & 8 & 7 & 15 & 16 & 18 & 18 & 16 & 14 & 12 & 13 \\
\hline & 3 & 12 & 10 & 9 & 8 & 8 & 8 & 12 & 13 & 2 & 2 \\
\hline & 4 & 1 & 1 & 6 & 6 & 0 & 1 & 4 & 4 & 5 & 5 \\
\hline \multirow{5}{*}{$\begin{array}{l}\text { Third } \\
\text { day }\end{array}$} & 0 & 22 & 22 & 13 & 14 & 6 & 7 & 4 & 5 & 6 & 8 \\
\hline & 1 & 11 & 11 & 18 & 18 & 15 & 14 & 16 & 15 & 10 & 10 \\
\hline & 2 & 6 & 5 & 12 & 11 & 17 & 15 & 13 & 12 & 21 & 18 \\
\hline & 3 & 6 & 7 & 1 & 1 & 7 & 8 & 11 & 12 & 7 & 8 \\
\hline & 4 & 0 & 0 & 1 & 1 & 0 & 1 & 1 & 1 & 1 & 1 \\
\hline \multirow{5}{*}{$\begin{array}{l}\text { Fifth } \\
\text { day }\end{array}$} & $\mathbf{0}$ & 35 & 32 & 30 & 30 & 10 & 9 & 19 & 20 & 8 & 8 \\
\hline & 1 & 5 & 5 & 14 & 12 & 21 & 17 & 17 & 15 & 19 & 20 \\
\hline & 2 & 4 & 7 & 1 & 2 & 8 & 14 & 7 & 7 & 11 & 10 \\
\hline & 3 & 1 & 1 & 0 & 1 & 6 & 5 & 1 & 1 & 4 & 4 \\
\hline & 4 & 0 & 0 & 0 & 0 & 0 & 0 & 1 & 2 & 3 & 3 \\
\hline
\end{tabular}




\section{DISCUSSION}

The main finding of this study was that the re-epithelialization rates and the measures of discomfort are not significantly different between the two bandage contact lenses. Although lower levels of conjunctival hyperemia and lens deposits was observed 5 days after PRK with PureVision lens; however, no superiority of any lens in lens centration, pain control or other investigated symptoms of eye discomfort was seen.

At first glance, the higher level of conjunctival hyperemia obtained with PureVision2 looks surprising despite its higher $\mathrm{Dk} / \mathrm{t}$ value. The $\mathrm{Dk} / \mathrm{t}$ value is only a numerical guideline used to anticipate lens performance on the eye and there is a non-linear relationship between this value and oxygen consumption of the cornea. A better practical index is oxygen flux which is the "true amount of oxygen which passes through a unit area of lens in a given time" which is dependent on the partial pressure driving force as well as the lens thickness and material permeability.[16] It has been reported that when $\mathrm{Dk} / \mathrm{t}$ of a lens reaches almost 90 , the curve of corneal physiological response to the lens flattens as the amount of oxygen available through the lens reaches atmospheric levels;[17] also modelling has demonstrated that a $85 \%$ difference in the Dk/t provides only $1 \%$ increase in corneal oxygen consumption.[8] In open-eye conditions, the maximum oxygen flux of PureVision of $\sim 98 \%$ will be similar to that of PureVision 2 . Therefore, more conjunctival hyperemia can be attributed to other causes such as the accumulation of more deposits rather than the $\mathrm{Dk} / \mathrm{t}$ of the newer lens in the present study.

More deposits with the PureVision2 lens was not an expected finding since a similar surface treatment of plasma oxidation treatment is used for both lenses and other parameters between these 
two contact lenses are similar. [8] It is possible the thicker lens interacted with the eyelids more, reducing the adherence of deposits.

The findings also indicated no difference in the rate of epithelial healing between two BCLs which was expected based on the similarity in the water content and the modulus of elasticity of the lenses.

Previous studies have focused on different lens materials and determined their effects after various forms of refractive surgery on the visual and ocular parameters (Table 6).[9, 11, 18-21] PureVision (Balafilcon A) was compared with other BCLs in several studies, but not with PureVision 2, therefore the confound of lens material and design has not been minimized.

Table 6: Comparison of epithelial wound healing and subjective symptoms of discomfort after various form of refractive surgery with different BCLs. (AA: Acuvue Advance (Galyfilcon A), PV: PureVision (Balafilcon A), FND: Focus Night \& Day (Lotrafilcon A), AO: Air Optix (Lotrafilcon B), PO: PermiO (Asmofilcon A), AcO: Acuvue Oasys (Senofilcon A), PV2: PureVision2 (Balafilcon A), B: (Comfilcon A))

\begin{tabular}{|c|c|c|c|c|c|c|}
\hline & Number & & & & & \\
\hline $\begin{array}{c}\text { Authors } \\
\text { (year) }\end{array}$ & $\begin{array}{c}\text { of } \\
\text { subjects } \\
\text { (eyes) }\end{array}$ & $\begin{array}{c}\text { Mean } \\
\text { age } \\
\text { (SD) }\end{array}$ & $\begin{array}{c}\text { BCLs } \\
\text { (materials) } \\
\text { examined }\end{array}$ & $\begin{array}{c}\text { Post-Op } \\
\text { follow- } \\
\text { ups } \\
\text { (days) }\end{array}$ & $\begin{array}{l}\text { Type of } \\
\text { surgery }\end{array}$ & Findings \\
\hline
\end{tabular}




\begin{tabular}{|c|c|c|c|c|c|c|}
\hline $\begin{array}{l}\text { Gil- } \\
\text { Cazorla et } \\
\text { al. } \\
(2008)[8]\end{array}$ & $22(44)$ & $\begin{array}{l}34.3 \\
(12.1)\end{array}$ & AA vs. PV & $1 \& 5$ & LASEK & $\begin{array}{c}\text { Greater lens deposits and } \\
\text { discomfort } 5 \text { days after LASEK } \\
\text { with PV, with no difference in } \\
\text { conjunctival hyperemia, lens } \\
\text { movement, uncorrected visual } \\
\text { acuity and epithelial healing }\end{array}$ \\
\hline $\begin{array}{l}\text { Grentzelo } \\
\text { s et al. } \\
(2009)[19]\end{array}$ & $44(88)$ & 28.5 & $\begin{array}{l}\text { FND vs. } \\
\text { AO }\end{array}$ & $\begin{array}{c}1,3 \& \\
5\end{array}$ & PRK & $\begin{array}{l}\text { No differences in corneal re- } \\
\text { epithelialization or subjective } \\
\text { symptoms between the lenses }\end{array}$ \\
\hline $\begin{array}{l}\text { Qu et al. } \\
(2011)[10]\end{array}$ & $21(42)$ & $\begin{array}{c}24 \\
(5.2)\end{array}$ & AA vs. PV & $1 \& 5$ & LASEK & $\begin{array}{l}\text { More comfort in terms of FB } \\
\text { sensation, pain, contact lens } \\
\text { intolerance and lower lens } \\
\text { deposits with the AA }\end{array}$ \\
\hline $\begin{array}{l}\text { Plaka et } \\
\text { al. } \\
\text { (2013)[14] }\end{array}$ & 47 (94) & $\begin{array}{l}29 \\
(10)\end{array}$ & AAPO & 1 to 4 & PRK & $\begin{array}{c}\text { Better epithelial wound healing } \\
\text { in terms of quickness and } \\
\text { smoothness with PO }\end{array}$ \\
\hline $\begin{array}{l}\text { Taylor et } \\
\text { al. } \\
(2014)[11]\end{array}$ & 54 (108) & 30.9 & $\begin{array}{l}\text { AcOvs. } \\
\text { AOvs. PV }\end{array}$ & $1 \& 4$ & PRK & $\begin{array}{c}\text { Least pain with } \mathrm{AcO} \text { followed } \\
\text { by AO and finally PV }\end{array}$ \\
\hline $\begin{array}{l}\text { Mohamm } \\
\text { adpour et } \\
\text { al. } \\
\text { (2015)[9] }\end{array}$ & $60(120)$ & 27.9 & AO vs. PV & $1 \& 3$ & PRK & $\begin{array}{l}\text { Significant pain on the first day } \\
\text { and FB sensation on days } 1 \text { and } \\
3 \text { with PV, no difference in } \\
\text { other symptoms of discomfort } \\
\text { including photophobia, tearing } \\
\text { and blurred vision }\end{array}$ \\
\hline
\end{tabular}




\begin{tabular}{|c|c|c|c|c|c|c|}
\hline $\begin{array}{l}\text { Eliacik et } \\
\quad \text { al. } \\
\text { (2015)[7] }\end{array}$ & $21(42)$ & $\begin{array}{l}26.4 \\
(5)\end{array}$ & B vs. AO & 1 to 5 & PRK & $\begin{array}{l}\text { significant better level of } \\
\text { comfort (with attention to pain, } \\
\text { photophobia and lacrimation) } \\
\text { and faster healing process with } \\
\text { B than AO }\end{array}$ \\
\hline $\begin{array}{l}\text { Mohamm } \\
\text { adpour et } \\
\text { al. } \\
\text { (2018)[21] }\end{array}$ & $60(120)$ & $\begin{array}{l}29.3 \\
(5.9)\end{array}$ & $\mathrm{AO}$ vs. $\mathrm{B}$ & $1 \& 3$ & PRK & $\begin{array}{l}\text { No difference in pain control } \\
\text { and discomfort between lenses, } \\
\text { less FB sensation with AO }\end{array}$ \\
\hline $\begin{array}{l}\text { Taneri et } \\
\text { al. } \\
(2018)[2]\end{array}$ & $15(15)$ & & $\begin{array}{l}\text { PV in one } \\
\text { eye }\end{array}$ & $1 \& 2$ & PRK & $\begin{array}{l}\text { Significant visual recovery and } \\
\text { less pain on day } 1 \text { using BCL. }\end{array}$ \\
\hline $\begin{array}{c}\text { Present } \\
\text { study }\end{array}$ & $45(90)$ & $\begin{array}{l}29.4 \\
(6.5)\end{array}$ & PV vs. PV2 & $\begin{array}{c}1,3 \& \\
5\end{array}$ & PRK & $\begin{array}{c}\text { Similar effect in managing of } \\
\text { pain, discomfort and epithelial } \\
\text { defect, higher incidence of } \\
\text { contact lens deposits and } \\
\text { conjunctival hyperemia using } \\
\text { PV2 }\end{array}$ \\
\hline
\end{tabular}

(SD: Standard deviation, BCL: Bandage contact lens, PRK: Photorefractive keratectomy, LASEK: Laser subepithelial keratomileusis, FB: Foreign body)

Difference in performance of Acuvue Advance (Galyfilcon A) and PureVision (Balafilcon A) has been attributed to the mechanical characteristics such as higher modulus (1.1 vs. $0.43 \mathrm{MPa}$ ), center thickness $(0.09$ vs. $0.07 \mathrm{~mm}$ ) of PureVision (Balafilcon A) lenses. $[8,10]$ Also, more deposits on PureVision lens's surface can increase subjective discomfort especially with attention to acuity during the contact lens wearing. $[8,10]$ However, due to the differences between LASEK and PRK, the results of these studies cannot be directly compared with the findings of current study; unlike 
LASEK, PRK causes more discomfort in the early post-operative period, longer visual recovery, and more haziness in patients with a similar correction range.[22]

Comparing pain / foreign body sensation after PRK using different BCLs, studies suggest it is higher with PureVision (Balafilcon A) compared to Acuvue Oasys (Senofilcon A) and Air Optix (Lotrafilcon B). $[9,11]$ The differences in oxygen permeability, oxygen transmissibility, water content, thickness and edge profile have been attributed as affective factors.[11] No differences in other symptoms that can be linked to discomfort including photophobia, tearing and blurred vision were noted.[9]

Generally, there are some links between discomfort and contact lens related factors such as design, material and lens care system. Some of lens design related factors are lens movement, base curve, edge alignment, edge profile and lens diameter.[23, 24] A major feature of the present study, which differentiates it from other similar studies, is the use of lenses with the same material composition. The Balafilcon A is composed of monomer poly-methylsiloxane (a vinyl carbamate derivative of TRIS) as silicone component associated with a hydrophilic hydrogel co-polymer known as N-vinyl pyrrolidone (NVP).[12] PureVision and PureVision2 are similar in Dk value, water content, modulus, base curve, edge profile (round), diameter and surface treatment. The only differences are their thickness and Dk/t (0.09 vs. 0.07; 101 vs. 130 for $-3.00 \mathrm{D}$ lens).[4, 25] Both lenses are approved by the FDA for up to 30 nights and continuous wear and also for therapeutic use in Europe.[13] 
In terms of tearing, despite a higher score of deposits on the surface of PureVision2 lens on the fifth day after PRK, but there was no statistically significant difference between the two lenses. This may be attributed to decreased corneal sensitivity after corneal excimer laser refractive surgery. Considering foreign body sensation, similar sensation was reported with both lenses, although PureVision is thicker, but the two lenses have the same tensile modulus. The edge profile was reported as an influential factor on subjective comfort and lens awareness but this factor was not applicable to the lenses used in the current study.[11]

The results of this study confirm the previous finding that when the Dk/t reaches almost 90, changes in Dk/t have a minimal effect on corneal physiological response. Therefore, selecting a BCL only based on its $\mathrm{DK} / \mathrm{t}$ in those with $\mathrm{DK} / \mathrm{t}$ near to 90 may not produce significant changes in the outcome, although the lens diameter or sagittal depth, lens modulus and etc. may appear as more influential factors on the subjective comfort.

In conclusion, according to PureVision and PureVision2 lens characteristics, the initial expectation was a better performance with PureVision2 at least in some of the parameters studied due to its thinner central thickness and higher oxygen transmission, however, this study shows that PureVision and PureVision2 contact lenses are equivalent as bandage lenses in the important aspects such as corneal re-epithelialization and subjective comfort. On the other hand, a higher inclination rate for deposits and conjunctival hyperemia with PureVision2 may indicate that the $\mathrm{Dk} / \mathrm{t}$ should not be the only features to be considered in selecting a BCL for early postoperative periods after refractive surgery.

\section{Acknowledgments}

The authors would like to thank participants who made this study possible. 


\section{REFERENCES}

[1] Kim JS, Na KS, Joo CK. Base curves of therapeutic lenses and their effects on post EpiLASIK vision and pain: a prospective randomized clinical trial. Jpn J Ophthalmol 2009;53:36873. PubMed PMID: 19763753. Epub 2009/09/19. eng.

[2] Taneri S, Oehler S, MacRae S, Dick HB. Influence of a Therapeutic Soft Contact Lens on Epithelial Healing, Visual Recovery, Haze, and Pain After Photorefractive Keratectomy. Eye Contact Lens 2018;44 Suppl 1:S38-S43. PubMed PMID: 27585399. Epub 2016/09/02. eng.

[3] Gil-Cazorla R, Arranz-Márquez E, Teus MA. Comparison of silicone and non-silicone hydrogel soft contact lenses used as a bandage after LASEK. Journal of Refractive Surgery 2008;24:199-203.

[4] Lim L, Tan DT, Chan WK. Therapeutic use of Bausch \& Lomb PureVision contact lenses. CLAO J 2001;27:179-85. PubMed PMID: 11725978. Epub 2001/12/01. eng.

[5] Mukherjee A, Ioannides A, Aslanides I. Comparative evaluation of Comfilcon A and Senofilcon A bandage contact lenses after transepithelial photorefractive keratectomy. Journal of optometry 2015;8:27-32.

[6] McDermott ML, Chandler JW. Therapeutic uses of contact lenses. Surv Ophthalmol 1989;33:381-94. PubMed PMID: 2655141. Epub 1989/03/01. eng.

[7] Eliacik M, Erdur SK, Gulkilik G, Ozsutcu M, Karabela Y. Compare the effects of two silicone-hydrogel bandage contact lenses on epithelial healing after photorefractive keratectomy with anterior segment optical coherence tomography. Cont Lens Anterior Eye 2015;38:215-9. PubMed PMID: 25707929. Epub 2015/02/25. eng.

[8] Gil-Cazorla R, Teus MA, Hernandez-Verdejo JL, De Benito-Llopis L, Garcia-Gonzalez M. Comparative study of two silicone hydrogel contact lenses used as bandage contact lenses after LASEK. Optom Vis Sci 2008;85:884-8. PubMed PMID: 18772724. Epub 2008/09/06. eng.

[9] Mohammadpour M, Amouzegar A, Hashemi H, Jabbarvand M, Kordbacheh H, Rahimi F, et al. Comparison of Lotrafilcon B and Balafilcon A silicone hydrogel bandage contact lenses in reducing pain and discomfort after photorefractive keratectomy: A contralateral eye study. Cont Lens Anterior Eye 2015;38:211-4. PubMed PMID: 25843674. Epub 2015/04/07. eng.

[10] Qu XM, Dai JH, Jiang ZY, Qian YF. Clinic study on silicone hydrogel contact lenses used as bandage contact lenses after LASEK surgery. Int J Ophthalmol 2011;4:314-8. PubMed PMID: 22553670. Pubmed Central PMCID: PMC3340826. Epub 2011/01/01. eng.

[11] Taylor KR, Caldwell MC, Payne AM, Apsey DA, Townley JR, Reilly CD, et al. Comparison of 3 silicone hydrogel bandage soft contact lenses for pain control after photorefractive keratectomy. J Cataract Refract Surg 2014;40:1798-804. PubMed PMID: 25217073. Epub 2014/09/14. eng. 
[12] Nilsson SE. Seven-day extended wear and 30-day continuous wear of high oxygen transmissibility soft silicone hydrogel contact lenses: a randomized 1-year study of 504 patients. CLAO J 2001;27:125-36. PubMed PMID: 11506437. Epub 2001/08/17. eng.

[13] Szaflik JP, Ambroziak AM, Szaflik J. Therapeutic use of a lotrafilcon A silicone hydrogel soft contact lens as a bandage after LASEK surgery. Eye Contact Lens 2004;30:59-62. PubMed PMID: 14722473. Epub 2004/01/15. eng.

[14] Plaka A, Grentzelos M, Astyrakakis N, Kymionis G, Pallikaris I, Plainis S. Efficacy of two silicone-hydrogel contact lenses for bandage use after photorefractive keratectomy. Contact Lens and Anterior Eye 2013;36:243-6.

[15] Shahinian L, Jr. Laser-assisted subepithelial keratectomy for low to high myopia and astigmatism. J Cataract Refract Surg 2002;28:1334-42. PubMed PMID: 12160801. Epub 2002/08/06. eng.

[16] Brennan NA. A model of oxygen flux through contact lenses. Cornea 2001;20:104-8. PubMed PMID: 11188991. Epub 2001/02/24. eng.

[17] Hill RM. Still Higher Dk/t Values Part 1. Can the Cornea Tell the Difference? International Contact Lens Clinic 1997:148-9.

[18] Mukherjee A, Ioannides A, Aslanides I. Comparative evaluation of Comfilcon A and Senofilcon A bandage contact lenses after transepithelial photorefractive keratectomy. J Optom 2015;8:27-32. PubMed PMID: 25649638. Pubmed Central PMCID: PMC4314622. Epub 2015/02/05. eng.

[19] Grentzelos MA, Plainis S, Astyrakakis NI, Diakonis VF, Kymionis GD, Kallinikos P, et al. Efficacy of 2 types of silicone hydrogel bandage contact lenses after photorefractive keratectomy. J Cataract Refract Surg 2009;35:2103-8. PubMed PMID: 19969215. Epub 2009/12/09. eng.

[20] Edwards JD, Bower KS, Sediq DA, Burka JM, Stutzman RD, Vanroekel CR, et al. Effects of lotrafilcon A and omafilcon A bandage contact lenses on visual outcomes after photorefractive keratectomy. J Cataract Refract Surg 2008;34:1288-94. PubMed PMID: 18655978. Epub 2008/07/29. eng.

[21] Mohammadpour M, Heidari Z, Hashemi H, Asgari S. Comparison of the Lotrafilcon B and Comfilcon A Silicone Hydrogel Bandage Contact Lens on Postoperative Ocular Discomfort After Photorefractive Keratectomy. Eye Contact Lens 2018;44 Suppl 2:S273-S6. PubMed PMID: 29438121. Epub 2018/02/14. eng.

[22] Ambrosio R, Jr., Wilson S. LASIK vs LASEK vs PRK: advantages and indications. Semin Ophthalmol 2003;18:2-10. PubMed PMID: 12759854. Epub 2003/05/22. eng.

[23] Young G, Garofalo R, Harmer O, Peters S. The effect of soft contact lens care products on lens modulus. Cont Lens Anterior Eye 2010;33:210-4. PubMed PMID: 20674468. Epub 2010/08/03. eng.

[24] Jones L, Brennan NA, Gonzalez-Meijome J, Lally J, Maldonado-Codina C, Schmidt TA, et al. The TFOS International Workshop on Contact Lens Discomfort: report of the contact lens materials, design, and care subcommittee. Invest Ophthalmol Vis Sci 2013;54:TFOS37-70. PubMed PMID: 24058138. Epub 2013/09/24. eng.

[25] Fonn D DK, Jones L, Toit RD, Sweeney D. . Silicone hydrogel material and surface properties. CL Spectrum 2002;17:24-8. 
Appendix 1: Subjective questionnaire.

\begin{tabular}{|c|c|c|c|c|c|}
\hline Symptoms & $\begin{array}{c}0 \\
\text { (Absence) }\end{array}$ & $\begin{array}{c}1 \\
\text { (Slight) }\end{array}$ & $\begin{array}{c}2 \\
\text { (Moderate) }\end{array}$ & $\begin{array}{c}3 \\
\text { (Sever) }\end{array}$ & $\begin{array}{c}4 \\
\text { (Very sever) }\end{array}$ \\
\hline Pain & & & & & \\
\hline Tearing & & & & & \\
\hline $\begin{array}{l}\text { Foreign body } \\
\text { sensation }\end{array}$ & & & & & \\
\hline Photophobia & & & & & \\
\hline Visual fluctuations & & & & & \\
\hline
\end{tabular}

